\title{
What drives the gap? Applying the Blinder-Oaxaca decomposition method to examine generational differences in transportation-related attitudes
}

\author{
Ali Etezady $^{1}$ (D) F. Atiyya Shaw ${ }^{1} \cdot$ Patricia L. Mokhtarian $^{1} \cdot$ Giovanni Circella $^{1,2}$
}

Published online: 25 January 2020

(c) The Author(s) 2020

\begin{abstract}
Considerable recent work suggests that Millennials' behaviors may be converging with those of Generation $\mathrm{X}$ as they enter later life stages, but few have investigated whether attitudes, which are often strong predictors of behavior, are undergoing the same convergence. In this study, we analyze the existing generational gap in four transportation-related attitudes (currently pro-urban, long-term pro-urban, pro-car ownership, and pro-environment), and examine the differential effects of other characteristics, including life-stage variables, on these attitudinal gaps. We apply the threefold Blinder-Oaxaca decomposition method to a statewide (weighted) sample of 1029 Millennials and 946 Generation Xers from California to unravel these effects. The method distinguishes among: (1) effects due to the cohorts having different characteristics (endowments); (2) effects due to those characteristics having different influences on attitudes (coefficients); and (3) the interaction of those two effects. We observe that Millennials' attitudes: (1) differ from those of Generation X only by small, albeit statistically significant, amounts on average; and (2) are closer to those of Generation $\mathrm{X}$ as they gain on a host of life-stage variables such as marital status, income, and education. For example, if Millennials were married, employed, and earning higher incomes at the same rates as Generation X (but retaining their own model coefficients), the generational gap in the currently pro-urban attitude would be reduced by $24 \%$. This study brings an econometric approach to the study of generational divides in transportationrelated attitudes, with findings suggesting that Millennials might be leaving part of their uniqueness behind as they enter later life stages.
\end{abstract}

Keywords Attitudes · Travel behavior · Millennials · Generation X · Generation Y · Generational differences $\cdot$ Generational divide $\cdot$ Blinder-Oaxaca decomposition

Electronic supplementary material The online version of this article (https://doi.org/10.1007/s1111 6-020-10080-5) contains supplementary material, which is available to authorized users.

Ali Etezady

etezady@gatech.edu

Extended author information available on the last page of the article 


\section{Introduction}

Although in modern times all generations have engendered a certain amount of media attention, the Millennials cohort has disproportionately enjoyed a spotlight so intense that, for many, the word "Millennials" now evokes something of an ad nauseum catchphrase. Examining the deluge of popular news, opinion, and academic pieces on Millennials makes it clear that this fascination can be traced to several attributes, the most notable of which is that Millennials will soon become the largest living adult cohort, a prediction with reverberating implications across all domains. Compounding this demographic dominance is the fact that members of this cohort have long been making choices that fly in the face of trends observed in prior generations, although several studies have suggested that some of these contrasting behaviors may be converging with those of prior generations as Millennials enter later life stages. Identified behavioral differences between Millennials (defined here as those born in the 1980s and 1990s; also known as Generation/Gen Y) and the preceding Generation X (born between 1965 and 1980; also referred to as Gen X) have been attributed to a range of personal (ex. attitudinal differences, technological exposure), environmental (ex. built environment policies intended to encourage denser living), and economic (ex. effects of recession) factors (Blumenberg et al. 2012; Delbosc et al. 2019; Kuhnimhof et al. 2012; Thigpen and Handy 2018).

Within transportation, there is substantial evidence that attitudes play a role in influencing behavioral choices (Spears et al. 2013; Domarchi et al. 2008; Kitamura et al. 1997; Kuppam et al. 1999; Mokhtarian and Salomon 1997). However, due largely to a lack of attitudinal data, the majority of comparative studies on generational differences have relied primarily on behavioral indicators, although there are segments of the literature that have examined market-oriented attitudes such as brand loyalty, or work/life-oriented attitudes such as satisfaction. We assert that continued examination of attitudinal differences between Millennials and Gen Xers is critical to placing into context behavioral differences, with particular importance in the transport sector where infrastructure planning revolves around forecasting travel behaviors, for which attitudes play an important explanatory role. But it is one thing to ascertain that attitudinal differences exist; it is another thing to identify the sources of those differences. That is the aim of the present study. To our knowledge, this paper is the first, in the dense collection of Millennials literature, to apply a decomposition approach, specifically the Blinder-Oaxaca (BO) method, to extricate group (endowment) and effect (coefficient) differences influencing transport-related attitudinal gaps between Millennials and Gen Xers. As such, while this study contributes specifically to the Millennials literature, it may also inform future work on other generational and demographic divides of interest within transport contexts.

The remainder of this paper is organized as follows: We first provide an overview of the literature on attitudinal and behavioral differences between Millennials and prior generations, followed by an introduction of the dataset. Next, we detail the attitudinal statements and resultant constructs examined in this paper, after which we statistically evaluate the mean generational differences for the selected attitudinal constructs. We then introduce and apply the Blinder-Oaxaca method to decompose significant generational gaps in attitudinal constructs, and close with limitations and avenues of future exploration for this work. We consign to a supplemental online Appendix the multiple underlying regression models (on which the $\mathrm{BO}$ analysis is based), detailed discussion on the decomposition of three of 
our four attitudes, and alternative versions of the BO method, so that the main body of the paper can concentrate attention on the distinctive features and messages of this study.

\section{Background}

Millennials have been studied extensively in the business and marketing domains, motivated by findings that Millennials are devoted consumerists, with increased tendencies to spend money easily and to view shopping as leisure (Belleau et al. 2007; Benckendorff 2010; Niehm and Ma 2006). In addition, Millennials have been found to have positive attitudes toward charitable organizations (Gorczyca and Hartman 2017) and to respond well to cause-related marketing (Liu and Ko 2011; Demetriou et al. 2010), insights that have been used by both philantrophic groups and for-profit businesses to target this consumer segment. Fueled by findings that Millennials are also more likely to report desires to travel abroad (Bilgihan 2016; Rita et al. 2018), hotel and airline sectors, among others, have set about studying traits such as brand loyalty, digital shopping attitudes and behaviors, and social media influences on Millennials' choices (Barton et al. 2013; Bilgihan 2016). In the workplace domain, notable findings show that Millennials place emphasis on achieving work-life balance in the form of a satisfying life outside of work (Ng et al. 2010; Straub et al. 2007), and in some regards value purpose over salary (McGlone et al. 2011).

Regarding transport and land use, Millennials have been capturing the attention of transportation professionals ever since they came of age, with increased preferences for living in urban centers (Delbosc and Nakanishi 2017; Okulicz-Kozaryn and Valente 2018), accompanied by reduced rates of licensure (Delbosc and Currie 2013; Sivak and Schoettle 2011, 2012), vehicle ownership, and vehicle miles traveled (VMT) (Hopkins 2016; Kuhnimhof et al. 2012; Polzin et al. 2014), leading to them being dubbed the "go-nowhere" generation (Buchholz and Buchholz 2012; McDonald 2015) (in contradiction to their afore-discussed penchant for traveling abroad). Recent work has suggested that differences in transport choices may be attributable to temporary environmental/external factors; for example, as Millennials enter later life stages (i.e., with children/families), lack of affordable options such as urban housing (among other reasons) may be causing their behavioral patterns to converge with those of prior generations (Delbosc and Nakanishi 2017; Garikapati et al. 2016; Lavieri et al. 2017). Relatedly, researchers have found that some behavioral differences may be due to economic factors, suggesting that as Millennials become more financially independent, attributes like vehicle ownership may converge with or even surpass those of prior generations (Klein and Smart 2017; Lavieri et al. 2017). External factors of influence that are less likely to change over time include recent policies intended to encourage smart development (ex. denser living), as well as increased alternatives/incentives for more sustainable modes (Delbosc and Currie 2013; Thigpen and Handy 2018). While it is critical to keep these external agents of influence in mind, several studies find that attitudes and/or cohort effects also contribute to differences such as the licensing decline (Delbosc and Currie 2013; Thigpen and Handy 2018), increased public transit usage (Hopkins 2016; Newbold and Scott 2018), and multimodality among Millennials (Circella et al. 2017a; Lee et al. 2019). 
Thus, we see that many of the attitudinal and behavioral studies of Millennials are motivated by the goal of understanding this generation as a core market segment, with the intent of capturing their loyalty (and dollars) as consumers. With similar motivations from the transport perspective, understanding generational divides is critical for engineers and planners as we work toward forecasting, planning, and designing infrastructure systems that must serve a multi-generational society, a large portion of whom are and will be from the Millennials cohort for several decades to come. This paper, accordingly, seeks to extend our understanding of such generational differences by focusing on transport-related attitudes among Millennials and Gen Xers, a topic which is less studied in the literature.

\section{Overview of dataset}

Data used in the analysis for this paper comes from the first wave (2015) of survey data obtained in a multi-year research effort designed to investigate emerging transportation trends in California with a focus on Millennials and Generation X. The survey was designed by a team of researchers at UC Davis and Georgia Tech, and then deployed to an online opinion panel obtained through a commercial vendor (who had an incentive system based on points awarded to survey respondents) with a quota sampling approach. Approximately 2400 total respondents $(\mathrm{N}=1975$ after excluding ineligible, inattentive, or incomplete cases; only members of the Millennial and Gen X cohorts were retained) were recruited across age groups, as well as across combinations of six geographic regions and three neighborhood types in California (the overall response rate equaled 46.3\%). The sampling process used targets for gender, age, race and ethnicity, household income, and presence of children in the household to capture as much of the population's diversity as possible. Further, to partially correct for sampling and nonresponse biases, the dataset was weighted to reflect the population distributions on several sociodemographic traits for Millennials and Gen Xers residing in California. Table 1 provides an overview of the descriptive statistics for the sample. Additional details regarding study implementation, survey variables, and sociodemographic distributions are presented in Circella et al. (2016, 2017b). 
Table 1 Selected sociodemographic characteristics of the sample $(\mathrm{N}=1975)$

\begin{tabular}{|c|c|c|c|c|c|c|c|c|c|}
\hline \multirow[t]{4}{*}{ Variable } & \multirow[t]{4}{*}{ Value } & \multicolumn{8}{|c|}{ Frequency $^{\mathrm{a}}$} \\
\hline & & \multicolumn{4}{|c|}{ Unweighted } & \multicolumn{4}{|c|}{ Weighted } \\
\hline & & \multicolumn{2}{|c|}{ Gen Y } & \multicolumn{2}{|c|}{ Gen $X$} & \multicolumn{2}{|c|}{ Gen Y } & \multicolumn{2}{|c|}{ Gen $X$} \\
\hline & & $\mathrm{N}$ & $\%$ & $\mathrm{~N}$ & $\%$ & $\mathrm{~N}$ & $\%$ & $\mathrm{~N}$ & $\%$ \\
\hline Gender & Female & 629 & 58.3 & 525 & 58.6 & 518 & 50.4 & 481 & 50.8 \\
\hline \multirow[t]{4}{*}{ Race } & White & 405 & 37.5 & 600 & 33.0 & 527 & 51.2 & 525 & 44.5 \\
\hline & Asian & 188 & 17.4 & 136 & 15.2 & 177 & 17.2 & 175 & 18.6 \\
\hline & Hispanic & 271 & 25.1 & 150 & 16.7 & 445 & 43.2 & 266 & 28.1 \\
\hline & African-American & 50 & 4.6 & 47 & 5.2 & 36 & 3.5 & 43 & 4.5 \\
\hline \multirow[t]{4}{*}{$\mathrm{Age}^{\mathrm{b}}$} & $18-24$ years & 335 & 31.0 & - & - & 400 & 38.9 & - & - \\
\hline & 25-34 years & 744 & 69.1 & - & - & 679 & 61.2 & - & - \\
\hline & $35-44$ years & - & - & 584 & 65.2 & - & - & 629 & 66.5 \\
\hline & $45-51$ years & - & - & 312 & 34.8 & - & - & 317 & 33.5 \\
\hline \multirow[t]{3}{*}{ Annual household income } & $<$ US $\$ 40 \mathrm{~K}$ & 351 & 32.5 & 207 & 23.1 & 329 & 33.0 & 183 & 19.4 \\
\hline & US $\$ 40-\$ 100 \mathrm{~K}$ & 472 & 43.8 & 414 & 46.2 & 385 & 37.3 & 342 & 36.2 \\
\hline & > US $\$ 100 \mathrm{~K}$ & 176 & 16.3 & 220 & 24.6 & 237 & 23.0 & 366 & 38.7 \\
\hline \multirow[t]{3}{*}{ Education } & High school diploma or less & 193 & 17.9 & 102 & 11.4 & 184 & 17.8 & 81 & 8.5 \\
\hline & College degree & 332 & 30.8 & 306 & 34.2 & 308 & 29.9 & 345 & 36.5 \\
\hline & Graduate degree and higher & 98 & 9.1 & 143 & 16.0 & 107 & 10.3 & 189 & 20.0 \\
\hline Employment & Employed & 689 & 63.9 & 612 & 68.3 & 796 & 77.4 & 796 & 84.2 \\
\hline \multirow[t]{4}{*}{$\mathrm{HH}$ size } & Single-person $\mathrm{HH}$ & 170 & 15.8 & 131 & 14.6 & 158 & 15.4 & 120 & 12.7 \\
\hline & Two-person HH & 267 & 24.7 & 203 & 22.7 & 244 & 23.7 & 212 & 22.4 \\
\hline & Three-person HH & 248 & 23.0 & 211 & 23.5 & 243 & 23.6 & 227 & 24.0 \\
\hline & Four-person or larger $\mathrm{HH}$ & 394 & 36.5 & 351 & 39.2 & 384 & 37.4 & 387 & 40.9 \\
\hline Marital status & Married & 412 & 38.2 & 557 & 62.2 & 370 & 36.0 & 606 & 64.1 \\
\hline \multirow[t]{3}{*}{ Built environment } & Urban dweller & 209 & 19.3 & 173 & 19.3 & 289 & 28.1 & 238 & 25.2 \\
\hline & Suburban dweller & 528 & 49.0 & 439 & 49.0 & 467 & 45.4 & 440 & 46.8 \\
\hline & Rural dweller & 342 & 31.7 & 284 & 31.7 & 270 & 26.4 & 264 & 28.0 \\
\hline \multirow[t]{2}{*}{ Political affiliation } & Republican & 183 & 17.0 & 196 & 21.9 & 153 & 14.8 & 180 & 19.0 \\
\hline & Democrat & 433 & 40.1 & 322 & 35.9 & 428 & 41.6 & 370 & 39.1 \\
\hline
\end{tabular}

${ }^{\mathrm{a}}$ Frequencies do not add up to $100 \%$ or the total $\mathrm{N}$ because of rounding errors, non-responses, or "other" categories

${ }^{\mathrm{b}}$ Average age (weighted sample): 33.8 years (median: 33.0 years); lowest age: 18 years; highest age: 51 years

\section{Attitudinal constructs}

The survey used in this study measured individual attitudes through 66 variables that collected information on a variety of topics such as adoption of technology, residential preferences, vehicle ownership, and travel behavior using a 5-point Likert-type scale ranging from "Strongly disagree" to "Strongly agree". Exploratory factor analysis (specifically, principal axis factoring with maximum likelihood estimation and oblique rotation) was first executed across the full set of statements (Circella et al. 2017b), after which confirmatory 


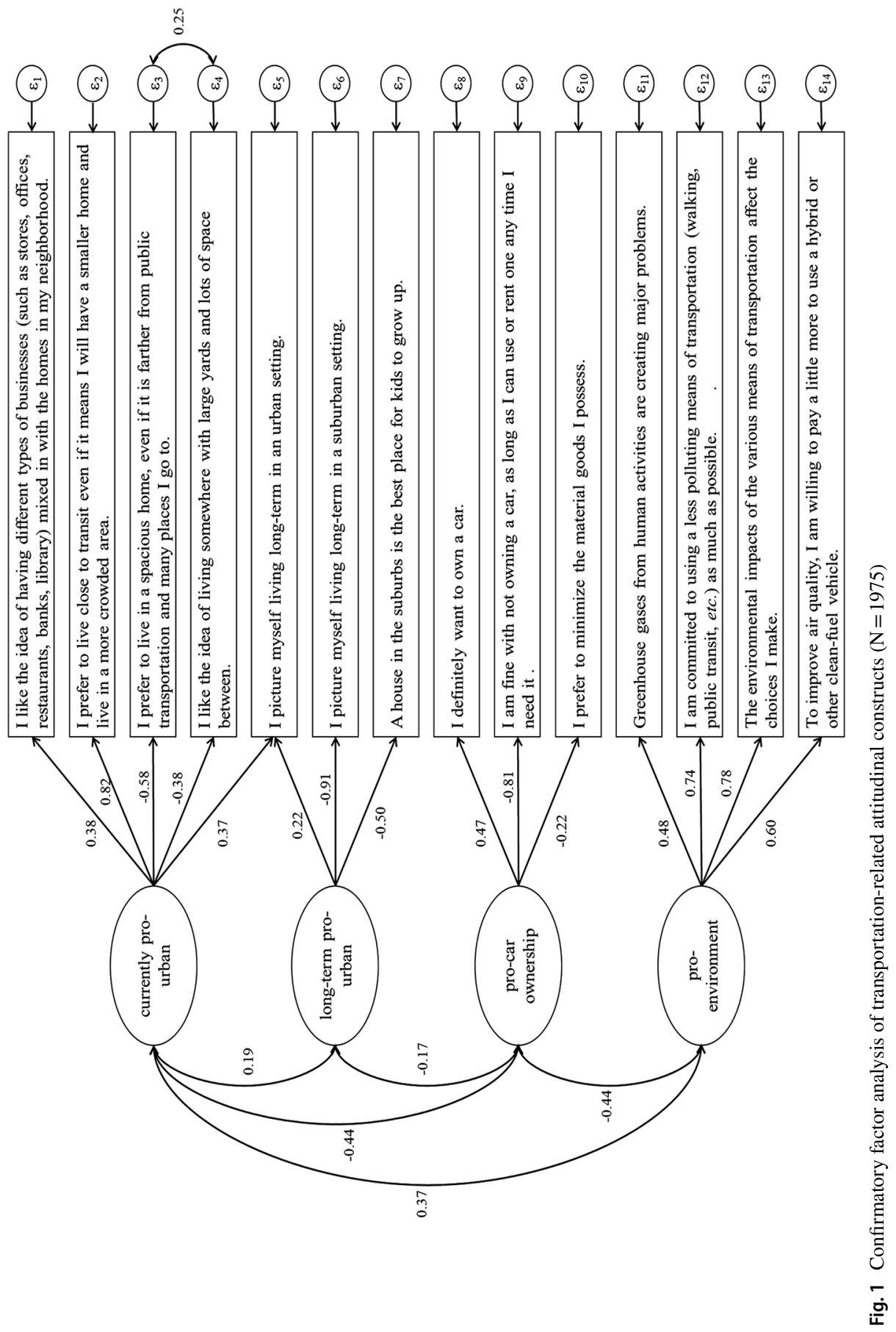


factor analysis (CFA) was applied across 14 of the initial 66 statements to extract four transportation-related constructs for further study. The selected attitudinal constructs represent desires for an urban lifestyle, separately in both present and future time frames, feelings toward owning a private vehicle, and attitudes toward environmentally conscious living. These constructs are selected due to their conceptual and/or empirical relationships with transport-related behaviors, and because they are also stereotypically expected to differ between Millennials and older cohorts (Delbosc and Nakanishi 2017; Forward et al. 2010; Hopkins 2016; Malokin et al. 2017; Shaw et al. 2019).

A visual representation of the constructs is shown in Fig. 1, which follows latent variable diagram convention with single-headed arrows representing the effects of constructs on observed indicators, and double-headed arrows representing correlations between variables (Loehlin 2004). Significant correlations between constructs are retained; item error correlations were also tested for significance, but most were ultimately restricted to zero (consistent with the assumption that the latent variable accounts for most of the correlation between items), with the exception of one significant error correlation shown in the diagram which both increases the fit of the model and is conceptually interpretable (i.e. having shared sources of unexplained variation between the respective statements is logical). The overall CFA model has acceptable fit with an RMSEA of 0.061 and a CFI of 0.902. Factor scores (continuous variables indicating respondents' relative measurements on each latent construct or factor) for the derived attitudinal constructs are computed using linear regression with the mean vector and covariance matrices from the fitted model (StataCorp 2017), and standardized across the sample to facilitate their interpretation. We discuss the meaning of each factor in turn.

\section{Currently pro-urban}

Numerous findings concur that Millennials have increased tendencies to prefer urban environments with denser land use (Delbosc and Nakanishi 2017; Okulicz-Kozaryn and Valente 2018), while their parents (i.e. Generation X) epitomize the suburban lifestyle, with their minivans and long commutes. This construct allows us to test that expectation with the current sample, as it reflects the mindset of respondents toward living in urban rather than suburban or rural areas-residential location choices that are critically tied to travel behavior (Ewing and Cervero 2010; Handy et al. 2005; Lavieri et al. 2017). As such, a higher score on this construct tends to signify a preference for living in mixed-use developments with high transit accessibility, even if it means sacrificing larger home and/or yard sizes.

\section{Long-term pro-urban (i.e., long-term urbanite)}

While the prior construct captures primarily current land-use preferences, this factor measures long-term preferences toward one's residential environment. As the statements indicate, a respondent with a higher score on this construct tends to see herself as living in an urban setting in the long term and tends not to consider a suburban setting as necessarily the best environment in which to settle down and raise children. This construct is informed by a statement shared with the prior factor (i.e. a double-loaded statement), the inclusion of which produces a substantial increase in fit, further improving the validity of the overall model. 


\section{Pro-car ownership}

As discussed in the "Background" section, a substantial body of work indicates that Millennials have been bucking the upward trend on car ownership and VMT (Buchholz and Buchholz 2012; Delbosc and Currie 2013; Kuhnimhof et al. 2012; McDonald 2015; Polzin et al. 2014; Sivak and Schoettle 2011, 2012), with recent concern in the literature about the stability of this deviation (Blumenberg et al. 2012; Delbosc and Nakanishi 2017; Garikapati et al. 2016; Lavieri et al. 2017; Newbold and Scott 2017). In this study, this construct measures attitudes toward car ownership, with one indicator related to general attitudes toward owning material goods. A respondent with a high score on this factor tends to prefer owning a car, tends not to be satisfied with just having access to a vehicle when needed, and tends not to feel the need to minimize material possessions. Overall, we see that positive attitudes toward car ownership are negatively correlated with the pro-urban and pro-environmental attitudes being studied, which is conceptually reasonable as the latter constructs are associated with favorable views toward sustainable modes of transport and denser residential locations that facilitate car-free or "car-lite" lifestyles.

\section{Pro-environment}

Previous studies have found that Millennials tend to be more environmentally conscious than prior generations-for example, they are more likely to support environmentallyfocused policies such as alternative energy (Rainie and Funk 2015). The literature, however, reports mixed results with respect to the influence of environmental consciousness on mobility decisions: while some find significant effects (Forward et al. 2010; Hopkins 2016), with more lasting implications compared to financial or situational effects (Hopkins 2016), others report little to no relationship between environmental attitudes and travel behavior (Anable 2005; Delbosc and Currie 2012). These differential conclusions may also be due to differences in sample constitution, experimental design, environmental attitude measurement, and choice of travel behavior studied.

Nevertheless, in view of the clear conceptual relationships between environmental awareness and travel behavior, as well as the intriguing clash of stereotypes represented by Millennials' greater environmental awareness coupled with their greater desire to travel abroad, we investigate differences in environmental attitudes between Millennials and Gen Xers. Three of the four statements measured by this construct are related to attitudes toward transportation mode and vehicle choice, while the fourth measures a general belief that greenhouse gases from human activities are creating problems. A respondent with a high score on this construct, therefore, tends to believe that there are environmental problems present, and tends to report being willing to alter his/her lifestyle and pay more to lead a more environmentally friendly life. We also see that this construct is positively correlated with positive views toward urban living in the present timeframe, but in line with findings from the literature, is negatively correlated with positive views toward car ownership. 


\section{Where is the gap?}

Having introduced the attitudinal constructs that are examined in this paper, we now analyze how each generation scores on these constructs and how large a gap, if any, exists between Millennials and Generation X in their attitudes. To this purpose, Table 2 summarizes the descriptive statistics and $t$ test results for differences in mean attitudinal factor scores between the generations being studied. One observation is that gaps in the mean scores for all four attitudinal constructs are not large, suggesting that generational differences in these attitudes may not be as pronounced as popular opinion has tended to portray. Nevertheless, the differences are statistically meaningful, even if modest. ${ }^{1}$ Figure 2 provides a more fine-grained look at the differences, by splitting the Millennials cohort into younger and older segments. For three of the four attitudes studied, a clear progression in attitudes from younger to older respondents can be seen.

As Table 2 illustrates, consistent with stereotype, Millennials on average have more favorable views toward currently living in urban locations than Generation X. The $t$ test on the difference in means between generations shows the gap to be statistically significant, implying that the -0.161 gap between the mean factor scores can be validly decomposed. Further dissection of the Millennials cohort on this construct, as demonstrated in Fig. 2, shows that "younger" Millennials (18-25 years old) have a larger mean factor score (0.215) compared to the "older" Millennials (26-34 years old), whose factor score averages 0.093 (thus putting older Millennials between younger Millennials and Gen X on the attitudinal continuum).

Table 2 Descriptive statistics and t-tests of differences in weighted means

\begin{tabular}{|c|c|c|c|c|c|c|}
\hline $\begin{array}{l}\text { Attitudinal con- } \\
\text { struct }\end{array}$ & Generation & $\begin{array}{l}\mathrm{N} \\
\text { (weighted) }\end{array}$ & Mean & SE & $\begin{array}{l}\text { Difference in } \\
\text { means }\end{array}$ & $\begin{array}{l}t \text {-statistic }{ }^{\mathrm{a}} \\
(p \text {-value })\end{array}$ \\
\hline \multirow{2}{*}{$\begin{array}{l}\text { Currently pro- } \\
\text { urban }\end{array}$} & Generation X & 946 & -0.010 & 0.046 & \multirow[t]{2}{*}{-0.161} & \multirow[t]{2}{*}{$-2.58(0.010)$} \\
\hline & Millennials & 1029 & 0.151 & 0.042 & & \\
\hline \multirow[t]{2}{*}{$\begin{array}{l}\text { Long-term pro- } \\
\text { urban }\end{array}$} & $\begin{array}{l}\text { Older } \\
\text { Millennials } \\
\text { and Genera- } \\
\text { tion X }\end{array}$ & 1490 & -0.093 & 0.035 & \multirow[t]{2}{*}{-0.149} & \multirow[t]{2}{*}{$-2.19(0.029)$} \\
\hline & $\begin{array}{l}\text { Younger } \\
\text { Millennials }^{\mathrm{b}}\end{array}$ & 485 & 0.056 & 0.058 & & \\
\hline \multirow{2}{*}{$\begin{array}{l}\text { Pro-car owner- } \\
\text { ship }\end{array}$} & Generation X & 946 & 0.037 & 0.047 & \multirow[t]{2}{*}{0.195} & \multirow[t]{2}{*}{$3.15(0.002)$} \\
\hline & Millennials & 1029 & -0.158 & 0.039 & & \\
\hline \multirow[t]{2}{*}{ Pro-environment } & Generation X & 946 & 0.043 & 0.047 & \multirow[t]{2}{*}{-0.149} & \multirow[t]{2}{*}{$-2.39(0.017)$} \\
\hline & Millennials & 1029 & 0.192 & 0.040 & & \\
\hline
\end{tabular}

${ }^{\mathrm{a}} t$ test statistic corresponding to differences in means between generations

${ }^{b}$ Younger Millennials represent those aged 18-25, while older Millennials represent those aged 26-34 years, all numbers relative to 2015 when the survey data was collected. As further discussed in the text, the generational divides reported in this table are those that are significant, and which will, accordingly, be decomposed in the next section

\footnotetext{
1 The differences in the table are essentially Cohen's d measures of effect size (because the latent constructs are standardized), which means that the gaps identified here would be classified as small effect sizes.
} 
Currently pro-urban

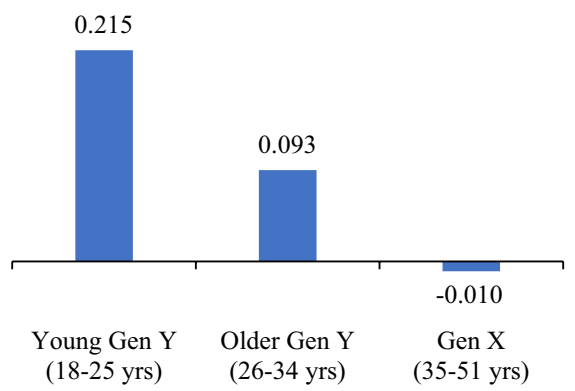

Pro-car ownership

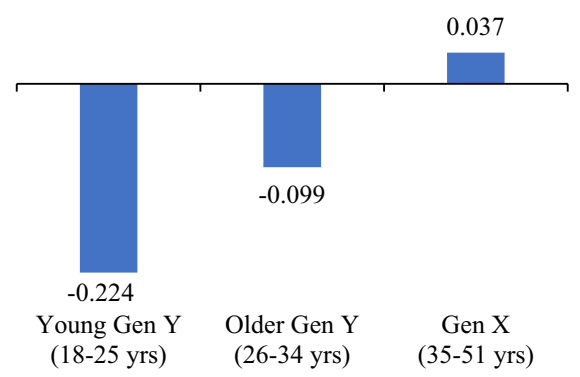

Long-term pro-urban

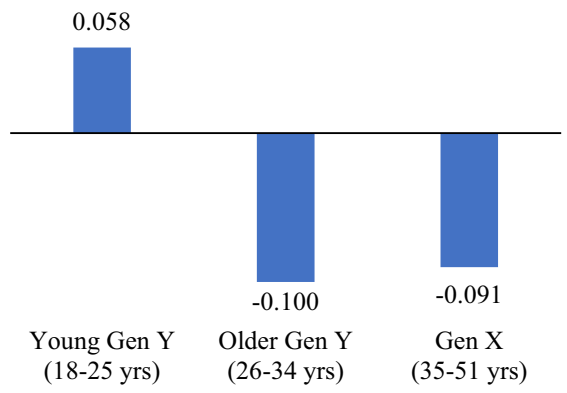

Pro-environment

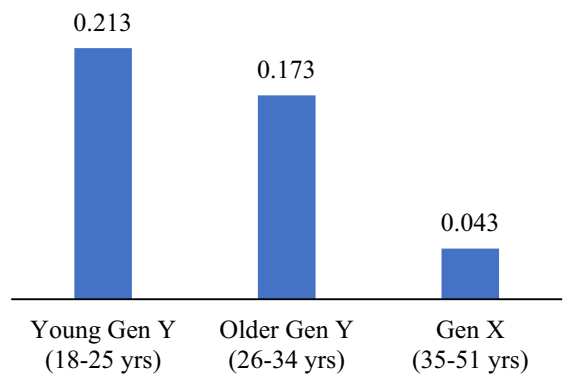

Fig. 2 Detailed comparison of mean attitudinal values among generations

Long-term attitudes toward one's living environment did not prove to be significantly different between Millennials and Generation X, but when we separated the younger Millennials (as previously demarcated) from the others, there was a more defined change. Younger Millennials, per Table 2 and Fig. 2, have a positive mean factor score, while older Millennials and members of Gen $\mathrm{X}$ have almost equal negative mean factor scores. The similarity between older Millennials $(-0.100)$ and Gen X $(-0.091)$ on this construct resembles the findings for the currently pro-urban construct previously discussed, in that it suggests a state of attitudinal transition. Therefore, for this attitude we combine older Millennials with Gen Xers, and decompose the statistically significant -0.149 difference in the mean values of the long-term urbanite attitude for that group versus the younger Millennials.

Attitudes regarding the desire to own a car are significantly different between the two generations (mean gap of -0.195), with Millennials (as expected) indicating that on average they are more averse to owning a personal vehicle. For this construct, as Fig. 2 shows, the mean factor score for younger Millennials $(-0.224)$ is more negative (farther from the Gen X mean of 0.037) than that of older Millennials (-0.099). Regarding environmental views between the two generations per se, we again see a statistically significant difference in attitudes $(-0.149)$, with Millennials being more environmentally conscious on average. For this variable, the difference between younger and older Millennials is relatively small, and not statistically significant. 
Based on the findings discussed in this section, attitudinal gaps between Millennials and Generation $\mathrm{X}$ are further analyzed for residential location choice attitudes in the present time frame, as well as for attitudes toward car ownership and the environment. However, for the long-term urban residential choice construct, we decompose the gap between younger Millennials and the aggregate group of older Millennials and Generation $\mathrm{X}$ instead, for reasons explained above.

Considering the clear progression of attitudinal means by generational cohort shown in Fig. 2, it is reasonable to ask, why not simply incorporate age as a continuous explanatory variable in a regression model for each attitude, interacted with at least some of the other variables in the model? Why artificially dichotomize a continuous variable into generation cohorts, thereby throwing away considerable information about its effects? We readily acknowledge the advantage of this alternative approach, and do not assert that our approach is unequivocally superior. Rather, we suggest that it has advantages of its own. First, for better or worse, it is common to analyze generations as discretely-defined cohorts rather than as falling along an age-based continuum, and so this study provides insight that is directly useful to this popular paradigm. Second, the gap decomposition approach clarifies and quantifies the sources of attitudinal differences more readily than would a regression model with continuously varying age and age interaction terms. Third, the present context offers a convenient and topical platform from which to highlight a methodology that, although little-used in transportation to date, has numerous potential applications in our field.

\section{Decomposing the gap}

Once ascertaining that there are significant differences (i.e. "gaps") in central tendency over time or across groups, it becomes compelling to investigate the sources or drivers of those differences. Going a step further requires us to ask, what are the differential effects of those explanatory variables on groups between which gaps have been identified? Ensuing from the seminal works of Oaxaca and Blinder (Blinder 1973; Oaxaca 1973), the Blinder-Oaxaca (BO) decomposition methods have been widely applied in economics to study similar topics, with a particular focus on the discriminatory behaviors of employers resulting in gender/racial wage gaps. To our knowledge, however, this study is the first within the transportation literature to employ this method, as well as the first in any field to apply it to attitudinal differences. In the following subsection, therefore, we provide a detailed overview of the method to illustrate its application and interpretation in a transportation context.

\section{Blinder-Oaxaca decomposition method}

We start with the common formulation of linear regression models, with variable $Y$ (in our case, each of the four attitudinal factor scores, respectively) modeled separately for two groups, $\mathrm{A}$ and $\mathrm{B}$ :

$$
Y_{A}=X_{A}^{\prime} \beta_{A}+\varepsilon_{A} \quad \text { and } \quad Y_{B}=X_{B}^{\prime} \beta_{B}+\varepsilon_{B} .
$$

Since the expected value of the error terms $\left(\varepsilon_{i}\right)$ in a linear regression containing a constant term will be zero, the difference in the mean values of the dependent variable between the two groups can be evaluated as: 


$$
\Delta E(Y)=E\left(Y_{A}\right)-E\left(Y_{B}\right)=E\left(X_{A}\right)^{\prime} \beta_{A}-E\left(X_{B}\right)^{\prime} \beta_{B} .
$$

All versions of the $\mathrm{BO}$ decomposition existing in the literature start from Eq. (2), and aim to rearrange and group the terms in a way that is conducive to better interpretation. The dominant decomposition philosophy is to try to understand which part of the gap in the outcome means (i.e., $\Delta E(Y))$ can be attributed to the difference in characteristics of each group (the explanatory variables), and which part may be attributed to the difference in the returns on (effects of) these characteristics (model coefficients). Following this philosophy, one may rewrite the sample version of Eq. (2) (i.e., replacing $E(X)$ with $\bar{X}$, and similarly for $Y$ ) using three terms:

$$
\Delta \bar{Y}=\left(\overline{X_{A}}-\overline{X_{B}}\right)^{\prime} \beta_{B}+{\overline{X_{B}}}^{\prime}\left(\beta_{A}-\beta_{B}\right)+\left(\overline{X_{A}}-\overline{X_{B}}\right)^{\prime}\left(\beta_{A}-\beta_{B}\right) .
$$

Equation (3) is known as the $\mathrm{BO}$ threefold decomposition written with respect to group B (the total mean difference could similarly be decomposed with respect to group $\mathrm{A}^{2}$; Jann 2008). In other words, group B's mean outcome (level of the dependent variable) is viewed as the baseline, and we are imagining, in effect, what it would take for the reference group B's mean outcome to converge to that of group A. In the context of the present study, group B represents Millennials today, and we are investigating what it would take for their mean attitudes to converge to those of Gen Xers (group A). We discuss each term of Eq. (3) in turn.

The first term in the decomposition shows the part of the gap related to group differences in the explanatory variables or endowments $(\mathrm{E})$ and is weighted by the vector of coefficients of group B. In other words, this term denotes the mean change in the level of the dependent variable of group B (Millennials) if this group had the values of the explanatory variables of group A (Gen Xers) (while holding its coefficients constant). The second term shows the portion of the gap stemming from the difference in the group coefficients (C) and, weighted by group B's vector of mean explanatory variables, indicates the mean change in the outcome of group $B$ if it had the coefficients of group $A$ (while holding its endowments constant). The final term denotes the portion of the total gap that exists due to the interaction (I) of differences in endowments and coefficients between the two groups. In other words, the interaction term indicates the (incremental) portion of the gap that occurs when both the endowments and coefficients change simultaneously; or, alternatively, the portion of the gap that remains after controlling for the endowment and coefficient portions (i.e. after controlling for the all-else-equal terms: the endowment contribution while holding the respective coefficients constant, and vice versa). An approximate standard error, in addition, may be computed for each of these decomposition terms (Jann 2008), although most studies using this method do not offer statistical test results. The reason, perhaps, is that we cannot equate a decomposition term to zero when it has a low statistical significance, since otherwise the summation of all the terms would not equal the total computed gap. Nevertheless, we provide the statistical significance as additional information in the "Results and discussion" section.

The interaction term is less conducive to a simple interpretation than the first two terms, and researchers have often disregarded it in their analysis. However, we believe it

\footnotetext{
${ }^{2}$ In that case, the proportions of the total gap associated with each of the three effects discussed below would differ, although the total gap itself would, of course, remain the same (with the sign reversed).
} 
is important not to neglect it, especially when-as is the case for us-it may account for a sizable fraction of the gap, and neglecting it therefore provides a substantially incomplete picture of the influences of the endowments and coefficients. One may interpret the interaction term as the differential effect of the change in endowments as $\beta$ goes from $\beta_{B}$ to $\beta_{A}$ [as shown in Eq. (4)], or similarly as the differential effect of the change in coefficients as the endowment goes from $\overline{X_{B}}$ to $\overline{X_{A}}$ [as shown in Eq. (5)]:

$$
\begin{gathered}
\left(\overline{X_{A}}-\overline{X_{B}}\right)^{\prime}\left(\beta_{A}-\beta_{B}\right)=\left(\overline{X_{A}}-\overline{X_{B}}\right)^{\prime} \beta_{A}-\left(\overline{X_{A}}-\overline{X_{B}}\right)^{\prime} \beta_{B} \\
={\overline{X_{A}}}^{\prime}\left(\beta_{A}-\beta_{B}\right)-{\overline{X_{B}}}^{\prime}\left(\beta_{A}-\beta_{B}\right) .
\end{gathered}
$$

Combining Eq. (4) with Eq. (3), we see that the endowment effect-the first term on the right-hand side (RHS) of Eq. (3) —is the group B "baseline endowment effect", while Eq. (4) is the incremental change from the group B baseline endowment effect if group B's coefficients as well as its endowments changed to match group A's. Alternatively, putting Eq. (5) together with Eq. (3), we see that the coefficient effect-the second term on the right-hand side (RHS) of Eq. (3) - is the group B "baseline coefficient effect", while Eq. (5) is the incremental change from the group B baseline coefficient effect if group B's endowments as well as its coefficients changed to match group A's.

If the interaction effect were zero, it would mean that the magnitude of the endowment effect does not differ by group, i.e. [from Eq. (4)] that:

$$
\left(\overline{X_{A}}-\overline{X_{B}}\right)^{\prime} \beta_{A}=\left(\overline{X_{A}}-\overline{X_{B}}\right)^{\prime} \beta_{B} \text {. }
$$

Put another way, it would signify that the mean change in the level of the dependent variable if group B "ended up with" the values of the explanatory variables of group A (while holding its coefficients constant) is the same as the mean change in the level of the dependent variable if group A had "started out with" the values of the explanatory variables of group B (while holding its coefficients constant). Alternatively, a zero interaction effect would mean that the coefficient effect does not differ by group, i.e. [from Eq. (5)] that:

$$
{\overline{X_{A}}}^{\prime}\left(\beta_{A}-\beta_{B}\right)={\overline{X_{B}}}^{\prime}\left(\beta_{A}-\beta_{B}\right) \text {. }
$$

In other words, it would indicate that the mean change in the level of the dependent variable if group B "ended up with" the coefficients of group A (while holding its endowments constant) is the same as the mean change in the level of the dependent variable if group A had "started out with" the coefficients of group B (while holding its endowments constant).

The literature on this method also contains another class of BO methods known as the twofold BO decomposition method. For a more detailed discussion of the twofold method, as well as details regarding why we execute the threefold method in this analysis, refer to Section 1 in the Appendix. 


\section{Results and discussion}

In this study, we apply the threefold BO decomposition [Eq. (3)], with the base group set to the Millennials, to investigate generational differences in attitudes. ${ }^{3}$ The segmented linear regression models, on which the decompositions are based, are estimated using sociodemographic and (when appropriate ${ }^{4}$ ) built environment characteristics, as these variables facilitate clearer interpretation of life-stage effects and are less likely than behavioral or other attitudinal variables to be endogenous. We first estimate segmented models (for Millennials and Generation $\mathrm{X}$ ) for each construct, and identify significant explanatory variables across the two regression models. We then test all identified significant variables in the decomposition model. To better focus on the decomposition results, we present the fully estimated regression models and more detailed discussion of them in Section 2 of the online Appendix, and bring only a brief overview of the models into the following sections.

As a general observation, it should be noted that the $\mathrm{R}^{2}$ goodness-of-fit measures for the models - i.e., the proportions of variance in attitudes that are explained by observed variablesare fairly modest (ranging from 0.058 to 0.143 ), albeit consistent with typical values for disaggregate travel behavior-related models. However, the composite contributions of the remaining, unobserved variables to the gap are accounted for as a difference in the constant term between cohorts. Although this is technically a difference in coefficient, in actuality the constant term will include (average) unobserved endowments, together with their coefficients. If the Millennials' constant term were to approach that of Gen Xers' over time, it would be unknown whether this were due to both unobserved endowments and the coefficients of those endowments converging to those of the Gen Xers, or whether changes in one of those things narrowed the gap while changes in the other widened it (but with the first effect predominating).

Table 3 provides a summary of the decompositions for the four attitudes studied in this paper. We discuss the results in greater detail for the currently pro-urban attitude to further demonstrate the interpretation of the decomposition method, but present the results only in more aggregate terms (life-stage variables versus all others) for the three remaining

Table 3 Summary of the decomposition of attitudinal gap results

\begin{tabular}{|c|c|c|c|c|c|c|}
\hline Attitudinal construct & Generation & Mean & $\begin{array}{l}\text { Gap (\% of } \\
\text { the total } \\
\text { gap) }\end{array}$ & $\begin{array}{l}\text { Endowment } \\
\text { (\% of the } \\
\text { total gap) }\end{array}$ & $\begin{array}{l}\text { Coefficient } \\
\text { (\% of the } \\
\text { total gap) }\end{array}$ & $\begin{array}{l}\text { Interaction } \\
\text { (\% of the } \\
\text { total gap) }\end{array}$ \\
\hline \multirow[t]{2}{*}{ Currently pro-urban } & Generation X & -0.010 & \multirow{2}{*}{$\begin{array}{l}-0.161 \\
100 \%\end{array}$} & \multirow{2}{*}{$\begin{array}{l}-0.052 \\
32 \%\end{array}$} & \multirow{2}{*}{$\begin{array}{l}-0.048 \\
30 \%\end{array}$} & \multirow{2}{*}{$\begin{array}{l}-0.061 \\
38 \%\end{array}$} \\
\hline & Millennials & 0.151 & & & & \\
\hline & Younger Millennials & 0.056 & & & & \\
\hline \multirow[t]{2}{*}{ Pro-car ownership } & Generation X & 0.037 & \multirow{2}{*}{$\begin{array}{l}0.195 \\
100 \%\end{array}$} & \multirow{2}{*}{$\begin{array}{l}0.082 \\
42 \%\end{array}$} & \multirow{2}{*}{$\begin{array}{l}-0.032 \\
-16 \%\end{array}$} & \multirow{2}{*}{$\begin{array}{l}0.145 \\
74 \%\end{array}$} \\
\hline & Millennials & -0.158 & & & & \\
\hline
\end{tabular}

\footnotetext{
3 The Oaxaca package (Jann 2008) in Stata version 15.1 was used to execute this analysis.

${ }^{4}$ Built environment variables were not included in the equations for the currently pro-urban attitude to avoid potential endogeneity. Accessibility measures such as Walk Score ${ }^{\circledR}$ or Bike Score ${ }^{\circledR}$ indices, the inclusion of which could potentially result in the same endogeneity problem, were nevertheless tested for all models (because there were conceptual grounds for inclusion), but their effects were not found to be statistically significant.
} 
attitudes. Grouping the "life-stage" variables together facilitates a better understanding of how Millennials' attitudes may change over time as a result of entering later life stages, while the "other" variables are less predictable in how they will change (or are impossible to change) over time. Section 3 in the online Appendix, however, provides the detailed discussion for these three remaining attitudes.

\section{Currently pro-urban attitude}

The segmented regression results for the currently pro-urban attitude, detailed in Section 2 of the Appendix, associate life-stage variables such as being married and having a higher income with a lower pro-urban tendency, while employment status shows a positive association. In addition, female Millennials tend to be significantly less pro-urban than their male counterparts, a trend that is not present (or significant) for Gen Xers. Moreover, Millennials who have a parent (or parents) with graduate-level education tend to be more prourban, while this influence is the opposite (though not significant) with Gen Xers, potentially pointing to a critical generational difference in how those raised in well-educated (higher-earning) households view the desirability of living in urban areas. With regard to race, Native Americans tend to be less pro-urban, while Asians tend to be more pro-urban, relative to other races.

Based on these regression results, Table 4 shows the aggregate decomposition results for the currently pro-urban attitude. The total gap for this attitude (Table 3 ) is -0.161 (standard deviations), with the three decomposition portions explaining approximately equal shares of this gap (i.e. about -0.05 each). The coefficient portion of the gap for each variable category, as shown in Table 4, is considerably larger in magnitude than its endowment counterpart. These larger contributions, however, add up to a comparatively smaller total coefficient contribution due to their opposite signs. To discuss these results in greater detail, Figs. 3, 4, and 5 present the detailed contribution of each variable to the gap. We discuss these results for each portion in the following subsections.

Table 4 Decomposition of the gap in currently pro-urban attitude, aggregated by variable type

\begin{tabular}{|c|c|c|c|c|}
\hline Variable category & $\begin{array}{l}\text { Endowment (\% of the } \\
\text { total gap) }\end{array}$ & $\begin{array}{l}\text { Coefficient (\% of the } \\
\text { total gap) }\end{array}$ & $\begin{array}{l}\text { Interaction ( } \% \text { of the } \\
\text { total gap) }\end{array}$ & $\begin{array}{l}\text { Total ( } \% \\
\text { of the total } \\
\text { gap) }\end{array}$ \\
\hline Life-stage $^{a}$ & $\begin{array}{l}-0.039 \\
(24 \%)\end{array}$ & $\begin{array}{l}-0.144 \\
(89 \%)\end{array}$ & $\begin{array}{l}-0.075 \\
(47 \%)\end{array}$ & $\begin{array}{l}-0.258 \\
(160 \%)\end{array}$ \\
\hline Other variables ${ }^{\mathrm{b}}$ & $\begin{array}{l}-0.013 \\
(8 \%)\end{array}$ & $\begin{array}{l}0.190 \\
(-118 \%)\end{array}$ & $\begin{array}{l}0.013 \\
(-8 \%)\end{array}$ & $\begin{array}{l}0.190 \\
(-118 \%)\end{array}$ \\
\hline Constant term & - & $\begin{array}{l}-0.093 \\
(58 \%)\end{array}$ & - & $\begin{array}{l}-0.093 \\
(58 \%)\end{array}$ \\
\hline Total & $\begin{array}{l}-0.052 \\
(32 \%)\end{array}$ & $\begin{array}{l}-0.048 \\
(30 \%)\end{array}$ & $\begin{array}{l}-0.061 \\
(38 \%)\end{array}$ & $\begin{array}{l}-0.161 \\
(100 \%)\end{array}$ \\
\hline
\end{tabular}

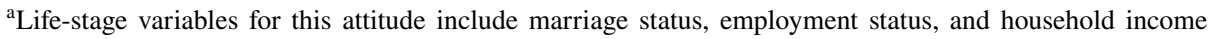
level

${ }^{\mathrm{b}}$ Other variables for this attitude include region of childhood upbringing, gender, race, parental education level, and political affiliation 


\section{Endowment}

As shown in Fig. 3, disparities in generational shares of high-income groups, political affiliation, employment status, and marital status contribute the most to the overall endowment portion of the gap. Those in higher-income households tend to have less favorable currently pro-urban attitudes (see regression results in the online Appendix); therefore, with Millennials currently lagging in earnings compared to Gen $\mathrm{X}$, we could expect their favorability toward currently pro-urban living to drop by as much as 0.032 (standard deviation units) if (all else equal) the Millennials' share of high income $(>\$ 100 \mathrm{~K})$ households matched Gen Xers' current share. In other words, the younger generation's attitude toward currently pro-urban living could close the gap (through becoming less pro-urban) by as much as $20 \%(-0.032 /-0.161=0.20)$ given these conditions. On the other hand, being employed has a positive effect on this attitudinal construct (see regression results in the Appendix), suggesting that if the employment rate among Millennials were to match that of their older peers (as they graduate and enter the workforce), they may on average (holding all else constant) become slightly more pro-urban (+0.011 s.d. units), thereby widening the gap by $7 \%$. With regard to marriage rates, we see that if Millennials were to have the same shares of marriage as Gen Xers, their favorability toward currently pro-urban living (all else equal again) would decrease by 0.019 s.d. units (narrowing the gap by $12 \%$ ).

Therefore, and as summarized in Table 4, the combined endowment impact of the three life-stage variables suggests that there may be an overall 0.039 s.d. (24\%) decrease in the gap (due to Millennials becoming less pro-urban) if Millennials entered the workforce, married, and earned higher incomes to the same extent as Gen Xers have currently done. Such predictions, needless to say, assume the temporal invariance of the Millennials' model coefficients. Testing the validity of these assumptions requires longitudinal data, and as with many other models in practice and literature, such insights into the future based on cross-sectional data should be interpreted with due caution.

Finally, with Republicans having a lower tendency to be pro-urban (according to the regression models), we see that the lower share of Republicans among the Californian Millennials (refer to Table 1$)$ accounts for approximately $38 \%(-0.020 /-0.052)$ of the endowment gap and $12 \%$ of the total gap.

High household income $(>\$ 100 \mathrm{~K})$

Republican

Married

Raised in Hawaii

Female

Democrat

Raised in Northeast

Asian

Parent w/ graduate education

Native American

Employed

Total

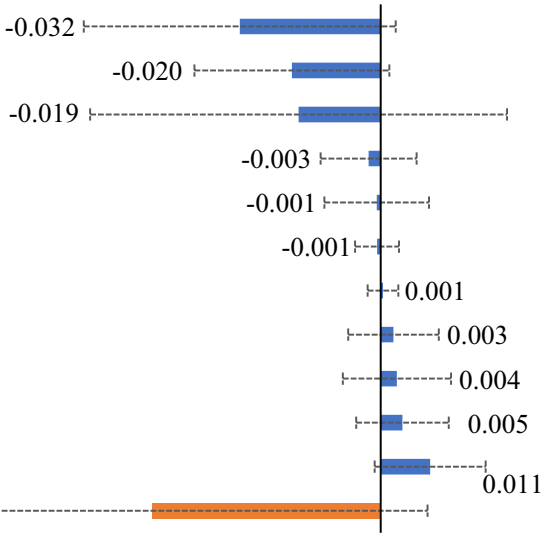

$-0.052$

Fig. 3 Contributions to the endowment portion of the difference in mean "currently pro-urban" attitude (horizontal dashed lines portray the $95 \%$ confidence interval) 


\section{Coefficient}

Figure 4 details the coefficient portion of the gap, with effect disparities of marital status, parental education level, political affiliation, and gender having relatively large contributions to the overall coefficient portion. Although both generations tend to be less pro-urban when married, this effect is stronger among Gen Xers, hence the decrease (all else equal) in Millennials' average "currently pro-urban" attitude if marriage were to influence their attitude similarly to the way it influences Gen Xers'. Meanwhile, Millennials having a parent with graduate-level education tend to be more "currently pro-urban", while Gen Xers with the same characteristics show the opposite effect, and so if Millennials had the coefficients of Gen Xers on these attributes, there would again be decreases in their overall attitude toward urban living.

Finally, we see that right-leaning political affiliations and gender (being female) both have a stronger negative effect on the pro-urban attitude among Millennials, hence, in this case if Millennials had the coefficients of Gen X on these attributes, there would be increases in their overall affinity for urban living. Thus, as illustrated in this discussion, the BO method facilitates an examination of not only the variables that are affecting pro-urban attitudes, but also the role of differential effects of the explanatory variables on the identified attitudinal differences between generations.

By further aggregating (by "life-stage" variables and "other" characteristics) the effects of the three terms, as shown in Table 4, we see that although the total coefficient effects are generally a bit smaller than the endowment effects ( -0.048 vs. -0.052 , respectively), the life-stage coefficient effect per se (at -0.144 s.d.) tends to be much larger than its endowment counterpart (0.039 s.d.). Such an aggregated decomposition can bring additional insight into how different groups of variables impact the gap differently.

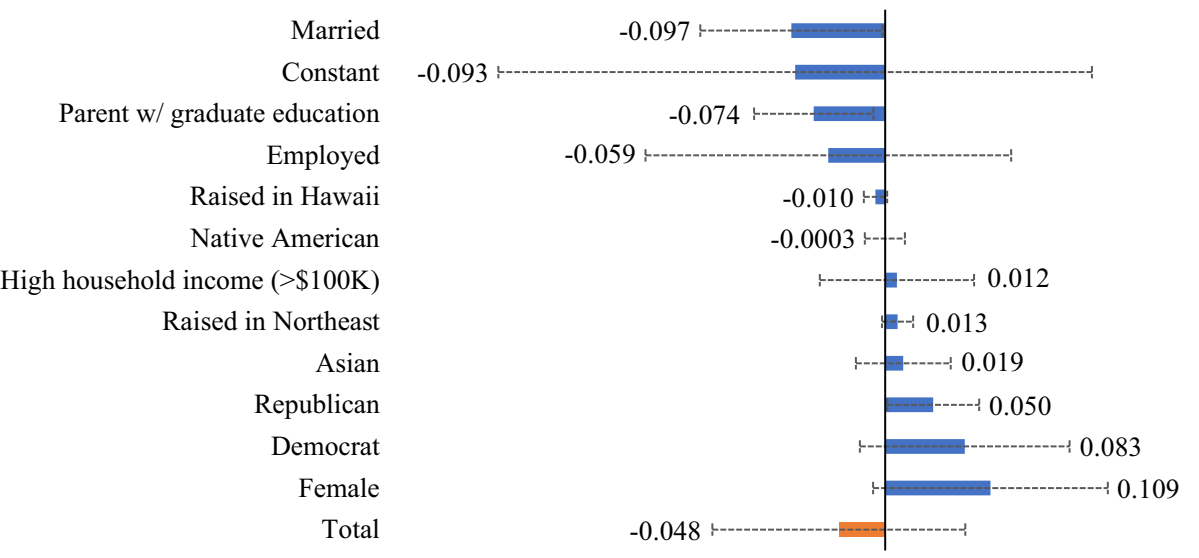

Fig. 4 Contributions to the coefficient portion of the difference in mean "currently pro-urban" attitude (horizontal dashed lines portray the $95 \%$ confidence interval) 


\section{Interaction}

With respect to the interaction term of -0.061 , as shown in Fig. 5, we can say that: the baseline endowment effect for Millennials is -0.052 (holding their coefficients constant but changing their endowments to those of the Gen Xers); and the baseline coefficient effect for Millennials is -0.048 (holding their endowments constant but changing their coefficients to those of the Gen Xers); but an additional effect of -0.061 is accrued if both their endowments and their coefficients were to change to those of the Gen Xers at the same time. The relative magnitude of this interaction effect (it is the largest component of the gap, accounting for $38 \%$ of it) demonstrates its importance.

We can also interpret the specific contribution of the most important variable in the interaction effect, namely marital status. As previously discussed, if Millennials were to achieve the same marriage rate as Gen Xers while keeping all coefficients constant (the endowment effect), the mean contribution to the total gap of -0.161 would be -0.019 , closing it by $12 \%$. If marital status were to have the same effect on the currently pro-urban attitude for Millennials as for Gen Xers while not changing their actual marriage rates (the coefficient effect), the mean contribution to the gap would be -0.097 , closing it by $60 \%$. But if both the marriage rate and the effect of marital status for Millennials converged to those of Gen Xers, the additional contribution to the gap would be -0.076 , closing it by a further $47 \%$ (the fact that the sum of these contributions exceeds $100 \%$ merely indicates that other explanatory variables contribute to widening the gap, as we saw with the endowment effect for employment status).

Republican
Parent w/ graduate education
Native American
Raised in Hawaii
Asian
Female
Raised in Northeast
Democrat
Employed
Married
Total

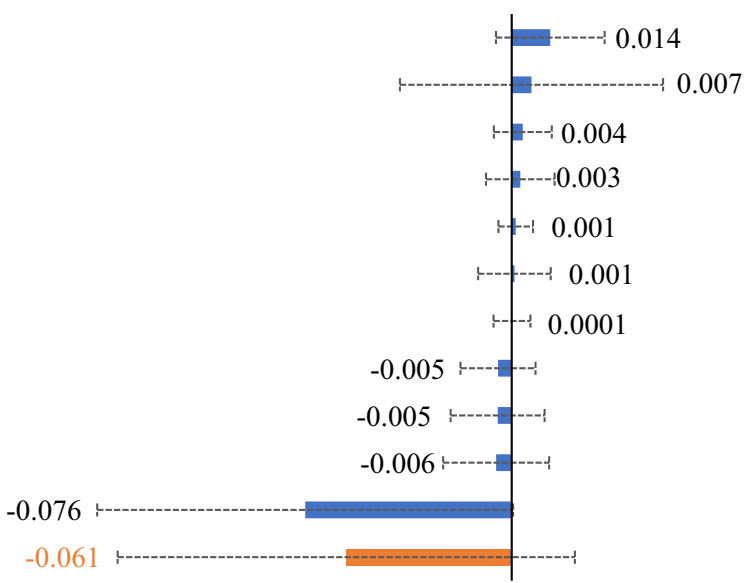

Fig. 5 Contributions to the interaction portion of the difference in mean "currently pro-urban" attitude (horizontal dashed lines portray the $95 \%$ confidence interval) 


\section{Long-term pro-urban attitude}

As discussed in the "Where is the gap?" section, the long-term pro-urban attitude is segmented based on the younger Millennials cohort ( $<26$ years old) relative to an aggregate group of older Millennials and Generation X. The group of life-stage variables significant in the linear regression models for this attitude includes marriage status, number of children (and the interaction of these two variables), income level, and education level. Other variables in the regression models include the region of childhood upbringing, race, built environment, and political affiliation. Table 5 shows the aggregate-by-category decomposition results for this attitude.

As Table 5 shows, the endowment effect of the life-stage variables is quite large, accounting for $181 \%$ of the total gap of -0.149 . This implies that if younger Millennials took on the same life-stage characteristics as their older peers but kept their own coefficients (all else constant), they could end up being even less favorable toward long-term living in urban areas than the older group.

The coefficient term for the life-stage variables is comparatively small, and points to the (perhaps more unlikely) scenario where only younger Millennials' returns on their characteristics change and match those of their older peers. In addition, the large magnitude of the interaction term here is mostly due to the "married $\times$ number of children" term, with the other interaction effects significantly smaller. This illustrates that the simultaneous change in the share and effect of this variable plays a large role in defining the gap in this attitude (for further discussion, refer to Section 3 in the online Appendix).

Table 5 Decomposition of the gap in long-term pro-urban attitude, aggregated by variable type

\begin{tabular}{lllll}
\hline Variable category & $\begin{array}{l}\text { Endowment (\% of the } \\
\text { total gap) }\end{array}$ & $\begin{array}{l}\text { Coefficient (\% of the } \\
\text { total gap) }\end{array}$ & $\begin{array}{l}\text { Interaction (\% of the } \\
\text { total gap) }\end{array}$ & $\begin{array}{l}\text { Total (\% } \\
\text { of the total } \\
\text { gap) }\end{array}$ \\
\hline Life-stage $^{\mathrm{a}}$ & -0.270 & 0.042 & 0.156 & -0.072 \\
Other variables & $(181 \%)$ & $(-28 \%)$ & $(-105 \%)$ & $(48 \%)$ \\
Constant term & 0.005 & -0.035 & -0.021 & -0.051 \\
Total & $-3 \%)$ & $(23 \%)$ & $(15 \%)$ & $(35 \%)$ \\
& - & -0.026 & - & -0.026 \\
& $(17 \%)$ & & -0.149 \\
\hline
\end{tabular}

${ }^{a}$ Life-stage variables for this attitude include marriage status, number of children, the interaction of the preceding two variables, income level, and education level

${ }^{\mathrm{b}}$ Other variables for this attitude include region of childhood upbringing, race, built environment, and political affiliation 


\section{Pro-car ownership attitude}

The life-stage variables associated with the pro-car ownership attitude include education-level variables (having only a high-school degree, and being a college student) and marital status, with the other variables significant in the regression models being region of childhood upbringing, race, built environment, employment type, and political affiliation. Based on these aggregated categories, Table 6 presents the aggregated decomposition results for this attitude.

The endowment portion of the life-stage variables, equal to $32 \%$ of the total gap of 0.195 s.d., indicates that with the Millennials graduating from college and obtaining higher degrees in addition to them getting married, we may see a higher average pro-car ownership among this cohort. The effect of coefficient change for this group, however, seems to be more impactful, pointing to a comparatively higher average pro-car ownership attitude if Millennials are to be influenced similarly as the Gen Xers when it comes to these life-stage variables. Such changes are much less certain than changes in average characteristics, and require longitudinal studies to ascertain the temporal stability of generational coefficients.

The interaction term for this group of variables has also a relatively large value here (0.106), due largely to the marital status variable. We see that the incremental effect (on top of the all-else equal terms) of the simultaneous change of endowments and coefficients for the life-stage variables would result in a more favourable pro-car ownership attitude for the Millennials.

Table 6 Decomposition of the gap in pro-car ownership attitude, aggregated by variable type

\begin{tabular}{lllll}
\hline Variable category & $\begin{array}{l}\text { Endowment (\% of the } \\
\text { total gap) }\end{array}$ & $\begin{array}{l}\text { Coefficient (\% of the } \\
\text { total gap) }\end{array}$ & $\begin{array}{l}\text { Interaction (\% of the } \\
\text { total gap) }\end{array}$ & $\begin{array}{l}\text { Total } \\
\text { of the total } \\
\text { gap) }\end{array}$ \\
\hline Life-stage $^{\mathrm{a}}$ & 0.062 & 0.107 & 0.106 & 0.275 \\
& $(32 \%)$ & $(55 \%)$ & $(54 \%)$ & $(141 \%)$ \\
Other variables & 0.020 & 0.020 & 0.038 & 0.078 \\
& $(10 \%)$ & $(10 \%)$ & $(19 \%)$ & $(40 \%)$ \\
Constant term & - & -0.158 & -0.158 \\
Total & $(-81 \%)$ & 0.145 & $(-81 \%)$ \\
& 0.082 & -0.032 & $(74 \%)$ & 0.195 \\
\end{tabular}

${ }^{\text {a }}$ Life-stage variables for this attitude include education-level variables (having only a high-school degree, and being a college student) in addition to marital status

${ }^{\mathrm{b}}$ Other variables for this attitude include region of childhood upbringing, race, built environment, employment type, and political affiliation 


\section{Pro-environment attitude}

In the case of pro-environmentalism, we see education status, income level, and employment status as the influential life-stage variables, and childhood upbringing region, race, and political affiliation constitute the other variable group that is significantly associated with pro-environmentalism. Based on these two variable categories, Table 7 shows the decomposition of the generational gap for this attitude.

In terms of the contribution of the life-stage endowment to the gap, we see, all else equal, a small effect of about 0.009 s.d. (6\% of the total gap), implying that we can expect little to no change in Millennials' average pro-environmentalism as their average shares of college graduates, employed, and higher incomes catch up with Gen Xers. The coefficient portion of the gap, however, has an outsize contribution, indicating that if Millennials end up being influenced similarly by the life-stage variables as their older peers (with all else equal), the younger generation would end up with even a lower pro-environment attitude than the Gen Xers, a scenario which is much less certain and as mentioned needs more investigation. Moreover, the incremental effect (on top of the all-else equal terms) of the simultaneous change of endowments/coefficients of the life-stage variables, as indicated by the interaction term, would close the gap by approximately $28 \%$, resulting in a less proenvironment Millennials generation as they grow older.

Table 7 Decomposition of the gap in pro-environment attitude, aggregated by variable type

\begin{tabular}{lllll}
\hline Variable category & $\begin{array}{l}\text { Endowment (\% of the } \\
\text { total gap) }\end{array}$ & $\begin{array}{l}\text { Coefficient (\% of the } \\
\text { total gap) }\end{array}$ & $\begin{array}{l}\text { Interaction (\% of the } \\
\text { total gap) }\end{array}$ & $\begin{array}{l}\text { Total (\% } \\
\text { of the total } \\
\text { gap) }\end{array}$ \\
\hline Life-stage & 0.009 & -0.275 & -0.042 & -0.308 \\
& $(6 \%)$ & $(185 \%)$ & $(28 \%)$ & $(207 \%)$ \\
Other variables & -0.055 & 0.175 & -0.008 & 0.112 \\
& $(37 \%)$ & $(-117 \%)$ & $(5 \%)$ & $(-75 \%)$ \\
Constant term & - & 0.047 & - & $(-32 \%)$ \\
& & $(-32 \%)$ & -0.050 & -0.149 \\
Total & -0.047 & -0.052 & $(34 \%)$ & $(100 \%)$ \\
\hline
\end{tabular}

${ }^{\mathrm{a}}$ Life-stage variables for this attitude include education status, income level, and employment status

${ }^{\mathrm{b}}$ Other variables for this attitude include region of childhood upbringing, race, and political affiliation 


\section{Conclusions and future work}

This study utilized data from a research survey executed in California to investigate generational differences in transportation-related attitudes, namely toward urban living (distinguishing between currently and long term), car ownership, and environmentally-conscious lifestyles. To our knowledge, it is the first transportation study to employ the Blinder-Oaxaca decomposition method, as well as the first in any field to apply it to attitudinal differences. One simple but important result is that on average, those differences are small (0.15-0.20 standard deviation units)—albeit statistically significant—suggesting that generational distinctions are not as dramatic as they have been portrayed to be by popular media. Nevertheless, it is of interest to explore the sources of the differences that do appear - and, separately from the substantive content of the results in this study, to demonstrate a flexible methodology for comparing two groups that has numerous potential applications in transportation beyond the present one.

We linearly decomposed the differences in mean attitudes between Millennials and Generation $\mathrm{X}$, and examined the decomposition terms which may be more likely to change as Millennials move into later life stages. The analysis shows that life-stage-related endowment disparities, such as in employment status, student status, income level, and marital status, explain significant portions of the overall attitudinal gaps. Our analysis also shows differential generational influences (coefficients) of these life-stage variables on attitudinal differences. We discussed interaction effects in greater depth than most gap decomposition studies do, and demonstrated the importance of considering such effects, highlighting the roles of the endowment and coefficient effects in concert with interactions.

In general, we can expect that the share of Millennials with life-stage characteristics such as being married will increase over time, i.e. that their endowment will approach that of Gen Xers (although, importantly, it may never reach Gen Xers', which has profound implications in a number of ways). It is much less clear how much the effect of such life-stage variables on an attitude will come to resemble that of Gen Xers' as Millennials continue to age. Effect magnitudes (coefficients), after all, are often functions of attitudes, lifestyles, and valuesand so we can imagine an infinite regress, in which we need to know how much certain attitudes will change in order to fully understand how much others will change.

With respect to the pro-environment attitudinal construct, we see that Millennials tend to be more environmentally conscious, and it is unlikely that convergence of their life-stage variable shares to those of the Gen Xers will significantly impact this tendency-although convergence of the coefficients of those variables would. On the other hand, changes in life-stage variables may decrease the stronger tendencies of the younger generation toward urban living in the present time frame. With respect to long-term pro-urban tendencies, the generational differences appear less clear. Although there is not a statistically meaningful difference between Millennials and Gen Xers in long-term pro-urban attitudes, the difference becomes meaningful when we compare younger Millennials ( $<26$ years old) to older Millennials combined with Gen Xers. The greater tendency of younger Millennials toward long-term urban living may be reversed as they get married and start to have children. Similarly, the pro-car ownership attitude among Millennials, currently lower than for Gen Xers, would diminish the gap by $32 \%$ if the younger generation were married and had college degrees to the same extent as their older counterparts.

This study represents one of the first examinations of the influence of life stage variables on Millennials' transportation-related attitudes, and complements existing literature findings that Millennials' behaviors may be converging to those of Generation X as they enter 
later life stages. As with most studies, the results of this one could be improved with the integration of additional explanatory variables, examples of which may include land use details for work location and neighborhood in which individuals were raised, among others. A limitation of this work revolves around the cross-sectional design of the survey, which precludes deductions about whether the coefficient portion of the gap is likely to diminish over time. The authors intend to extend the application of the Blinder-Oaxaca approach to longitudinal data in the future. A further useful extension (particularly in a new dataset with broader reach) would be to decompose differences between geographically distinct (both in terms of living and working locations) groups, where geography may be at a scale ranging from international to type of neighborhood: what are the sources of differences in attitude between urban versus rural residents or workers, or between residents of one country versus another? Additionally, as a number of studies (e.g. Myers 2016) indicate, the real-world impact of these attitudes and preferences would be determined by contextual factors, therefore future work that builds upon findings in this paper will seek to investigate how much of the reduction in attitudinal gaps translates into behavioral choices. This intended extension would have direct policy implications, since policy-makers are often more interested in revealed behavioral choices.

As such, the results of the current study pave the way toward better understanding of whether, why, and how travel-related behaviors or choices differ between generations. Such studies have important implications for transportation planning and forecasting, and further examination of differences in behaviors and attitudes across generational divides using longitudinally-designed studies should be a priority for transportation researchers moving forward.

Acknowledgements This paper is a substantial expansion of an earlier version presented at the 98th Annual Transportation Research Board meeting. This paper has been improved by comments from several anonymous reviewers. The survey used in this study was funded by the National Center for Sustainable Transportation, with additional funding from UC Davis Sustainable Transportation Energy Pathways. Any opinions, findings, or recommendations expressed are those of the authors and do not necessarily reflect the views of the sponsors. The authors are grateful to those involved in the survey design, data collection, data entry/ cleaning, and preliminary analyses, especially Drs. Farzad Alemi and Yongsung Lee, in addition to Kate Tiedeman and Rosaria Berliner. Application of the Blinder-Oaxaca decomposition method to our context was inspired by an unpublished presentation by Dr. Noreen McDonald. The authors hereby indicate that they have no conflicts of interests associated with this work.

Open Access This article is licensed under a Creative Commons Attribution 4.0 International License, which permits use, sharing, adaptation, distribution and reproduction in any medium or format, as long as you give appropriate credit to the original author(s) and the source, provide a link to the Creative Commons licence, and indicate if changes were made. The images or other third party material in this article are included in the article's Creative Commons licence, unless indicated otherwise in a credit line to the material. If material is not included in the article's Creative Commons licence and your intended use is not permitted by statutory regulation or exceeds the permitted use, you will need to obtain permission directly from the copyright holder. To view a copy of this licence, visit http://creativecommons.org/licenses/by/4.0/.

\section{References}

Anable, J.: 'Complacent car addicts' or 'aspiring environmentalists'? Identifying travel behaviour segments using attitude theory. Transp. Policy 12(1), 65-78 (2005). https://doi.org/10.1016/j.tranp ol.2004.11.004

Barton, C., Haywood, J., Jhunjhunwala, P., Bhatia, V.: Traveling with Millennials. Retrieved in July 2018 from The Boston Consulting Group: https://www.bcg.com/documents/file129974.pdf (2013) 
Belleau, B.D., Summers, T.A., Yingjiao, X., Pinel, R.: Theory of reasoned action: purchase intention of young consumers. Cloth. Text. Res. J. 25(3), 244-257 (2007). https://doi.org/10.1177/0887302x07302768

Benckendorff, P.J.: Tourism and Generation Y. CAB International, Cambridge (2010)

Biewen, M.: A general decomposition formula with interaction effects. Appl. Econ. Lett. 21(9), 636-642 (2014). https://doi.org/10.1080/13504851.2013.879280

Bilgihan, A.: Gen Y customer loyalty in online shopping: an integrated model of trust, user experience and branding. Comput. Hum. Behav. 61, 103-113 (2016). https://doi.org/10.1016/j.chb.2016.03.014

Blinder, A.S.: Wage discrimination: reduced form and structural estimates. J. Hum. Resour. 8(4), 436-455 (1973). https://doi.org/10.2307/144855

Blumenberg, E., Taylor, B.D., Smart, M., Ralph, K., Wander, M., Brumbaugh, S.: What's Youth Got to Do with It? Exploring the Travel Behavior of Teens and Young Adults. UC Berkeley, University of California Transportation Center. Retrieved in July 2018 from: https://escholarship.org/uc/item/9c14p $6 \mathrm{~d} 5$ (2012)

Braumoeller, B.F.: Hypothesis testing and multiplicative interaction terms. Int. Org. 58(4), 807-820 (2004)

Buchholz, T.G., Buchholz, V.: The Go-Nowhere Generation. The New York Times. Retrieved in July 2018 from https://www.nytimes.com/2012/03/11/opinion/sunday/the-go-nowhere-generation.html (2012)

Circella, G., Fulton, L., Alemi, F., Berliner, R.M., Tiedeman, K., Mokhtarian, P.L., Handy, S.: What Affects Millennials' Mobility? Part I: Investigating the Environmental Concerns, Lifestyles, Mobility-Related Attitudes and Adoption of Technology of Young Adults in California. UC Davis, National Center for Sustainable Transportation. Retrieved in July 2018 from: https://ncst.ucdavis.edu/wp-content/uploa ds/2014/08/05-26-2016-NCST_Report_Millennials_Part_I_2016_May_26_FINAL1.pdf (2016)

Circella, G., Alemi, F., Berliner, R.M., Tiedeman, K., Lee, Y., Fulton, L., Handy, S., Mokhtarian, P.L.: Multimodal behavior of Millennials: exploring differences in travel choices between young adults and Gen-Xers in California. In: Paper Presented at the 96th Annual Meeting of the Transportation Research Board, Washington DC, (2017a)

Circella, G., Alemi, F., Tiedeman, K., Berliner, R. M., Lee, Y., Fulton, L., Handy, S.: What Affects Millennials' Mobility? Part II: The Impact of Residential Location, Individual Preferences and Lifestyles on Young Adults' Travel Behavior in California. UC Davis, National Center for Sustainable Transportation. Retrieved in July 2018 from: https://ncst.ucdavis.edu/wp-content/uploads/2015/09/ NCST_Report_Millennials_Part_II_2017_March_31_FINAL.pdf (2017b)

Delbosc, A., Currie, G.: Using Online Discussion Forums to Study Attitudes toward Cars and Transit among Young People in Victoria. Paper presented at the Australasian Transport Research Forum, Perth, Australia, (2012)

Delbosc, A., Currie, G.: Causes of youth licensing decline: a synthesis of evidence. Transp. Rev. 33(3), 271-290 (2013). https://doi.org/10.1080/01441647.2013.801929

Delbosc, A., Nakanishi, H.: A life course perspective on the travel of australian Millennials. Transp. Res. Part A: Pol. Pract. 104, 319-336 (2017). https://doi.org/10.1016/j.tra.2017.03.014

Delbosc, A., McDonald, N., Stokes, G., Lucas, K., Circella, G., Lee, Y.: Millennials in cities: comparing travel behaviour trends across six case study regions. Cities 90, 1-14 (2019)

Demetriou, M., Papasolomou, I., Vrontis, D.: Cause-related marketing: building the corporate image while supporting worthwhile causes. J. Brand Manag. 17(4), 266 (2010). https://doi.org/10.1057/bm.2009.9

Domarchi, C., Tudela, A., González, A.: Effect of attitudes, habit and affective appraisal on mode choice: an application to university workers. Transportation 35(5), 585-599 (2008). https://doi. org/10.1007/s11116-008-9168-6

Ewing, R., Cervero, R.: Travel and the built environment. J. Am. Plann. Assoc. 76(3), 265-294 (2010). https://doi.org/10.1080/01944361003766766

Fan, Y., Guthrie, A., Levinson, D.: Waiting time perceptions at transit stops and stations: effects of basic amenities, gender, and security. Transp. Res. Part A Pol. Pract. 88, 251-264 (2016). https://doi. org/10.1016/j.tra.2016.04.012

Forward, S., Aretun, Å., Engström, I., Nolén, S., Nolén, S.: Young People's Attitudes toward Acquiring a Driving License. (VTI Report 694/2010). Linkoping, Sweden: The Swedish National Road and Transport Research Institute (VTI), (2010)

Fry, R.: Millennials Are the Largest Generation in the U.S. Labor Force. Washington, D.C., Pew Research Center. Retrieved in July 2018 from: http://www.pewresearch.org/fact-tank/2018/04/11/ millennials-largest-generation-us-labor-force/ (2018)

Garikapati, V.M., Pendyala, R.M., Morris, E.A., Mokhtarian, P.L., McDonald, N.: Activity patterns, time use, and travel of Millennials: a generation in transition? Transp. Rev. 36(5), 558-584 (2016). https://doi.org/10.1080/01441647.2016.1197337 
Gorczyca, M., Hartman, R.L.: The new face of philanthropy: the role of intrinsic motivation in Millennials' attitudes and intent to donate to charitable organizations. J. Nonprofit Publ. Sect. Mark. 29(4), 415-433 (2017). https://doi.org/10.1080/10495142.2017.1326349

Handy, S., Cao, X., Mokhtarian, P.: Correlation or causality between the built environment and travel behavior? Evidence from Northern California. Transp. Res. Part D Transp. Environ. 10(6), 427444 (2005). https://doi.org/10.1016/j.trd.2005.05.002

Hopkins, D.: Can environmental awareness explain declining preference for car-based mobility amongst Generation Y? A qualitative examination of learn to drive behaviours. Transp. Res. Part A 94(C), 149-163 (2016). https://doi.org/10.1016/j.tra.2016.08.028

Jann, B.: The Blinder-Oaxaca decomposition for linear regression models. Stata J. 8(4), 453-479 (2008)

Kitamura, R., Mokhtarian, P., Laidet, L.: A micro-analysis of land use and travel in five neighborhoods in the San Francisco bay area. Transportation 24(2), 125-158 (1997). https://doi.org/10.1023/a:10179 59825565

Klein, N.J., Smart, M.J.: Millennials and car ownership: less money, fewer cars. Transp. Pol. 53, 20-29 (2017). https://doi.org/10.1016/j.tranpol.2016.08.010

Kuhnimhof, T., Armoogum, J., Buehler, R., Dargay, J., Denstadli, J.M., Yamamoto, T.: Men shape a downward trend in car use among young adults-evidence from six industrialized countries. Transp. Rev. 32(6), 761-779 (2012). https://doi.org/10.1080/01441647.2012.736426

Kuppam, A.R., Pendyala, R.M., Rahman, S.: Analysis of the role of traveler attitudes and perceptions in explaining mode-choice behavior. Transp. Res. Rec. 1676, 68-76 (1999). https://doi. org/10.3141/1676-09

Lavieri, P.S., Garikapati, V.M., Bhat, C.R., Pendyala, R.M.: Investigation of heterogeneity in vehicle ownership and usage for the millennial generation. Transp. Res. Rec. J. Transp. Res. Board 2664, 91-99 (2017). https://doi.org/10.3141/2664-10

Lee, Y., Circella, G., Mokhtarian, P.L., Guhathakurta, S.: Are Millennials more multimodal? A latentclass cluster analysis with attitudes and preferences among millennial and Generation X commuters in California. Transportation. (2019). https://doi.org/10.1007/s11116-019-10026-6

Liu, G., Ko, W.W.: An analysis of cause-related marketing implementation strategies through social alliance: partnership conditions and strategic objectives. J. Bus. Ethics 100(2), 253-281 (2011). https ://doi.org/10.1007/s10551-010-0679-7

Loehlin, J.C.: Latent Variable Models: An Introduction to Factor, Path, and Structural Equation Analysis. Taylor \& Francis, New York (2004)

Malokin, A., Circella, G., \& Mokhtarian, P.L.: Do Multitasking Millennials Value Travel Time Differently? A Revealed Preference Study of Northern California Commuters. In: Paper presented at the 96th Annual Meeting of the Transportation Research Board, Washington DC (2017)

McDonald, N.C.: Are Millennials really the "go-nowhere" generation? J. Am. Plann. Assoc. 81(2), 90-103 (2015). https://doi.org/10.1080/01944363.2015.1057196

McGlone, T., Spain, J.W., McGlone, V.: Corporate social responsibility and the Millennials. J. Educ. Bus. 86(4), 195-200 (2011). https://doi.org/10.1080/08832323.2010.502912

Mokhtarian, P.L., Salomon, I.: Modeling the desire to telecommute: the importance of attitudinal factors in behavioral models. Transp. Res. Part A Pol. Pract. 31(1), 35-50 (1997). https://doi.org/10.1016/ S0965-8564(96)00010-9

Myers, D.: Peak Millennials: three reinforcing cycles that amplify the rise and fall of urban concentration by Millennials. Hous. Pol. Debate 26(6), 928-947 (2016). https://doi.org/10.1080/10511 482.2016.1165722

Newbold, K.B., Scott, D.M.: Driving over the life course: the automobility of Canada's Millennial, Generation X, Baby Boomer and Greatest Generations. Travel Behav. Soc. 6, 57-63 (2017). https://doi. org/10.1016/j.tbs.2016.06.003

Newbold, K.B., Scott, D.M.: Insights into public transit use by Millennials: the Canadian experience. Travel Behav. Soc. 11, 62-68 (2018). https://doi.org/10.1016/j.tbs.2017.12.009

Ng, E.S.W., Schweitzer, L., Lyons, S.T.: New generation, great expectations: a field study of the Millennial Generation. J. Bus. Psychol. 25(2), 281-292 (2010). https://doi.org/10.1007/s1086 9-010-9159-4

Niehm, L.S., Ma, Y.J.: Service expectations of older generation Y customers: an examination of apparel retail settings. Manag. Serv. Qual. Int. J. 16(6), 620-640 (2006). https://doi.org/10.1108/09604 520610711936

Oaxaca, R.: Male-female wage differentials in urban labor markets. Int. Econ. Rev. 14(3), 693-709 (1973). https://doi.org/10.2307/2525981

Okulicz-Kozaryn, A., Valente, R.R.: No urban malaise for Millennials. Reg. Stud. 53(2), 1-11 (2018). https://doi.org/10.1080/00343404.2018.1453130 
Polzin, S.E., Chu, X., Godfrey, J.: The impact of Millennials' travel behavior on future personal vehicle travel. Energy Strategy Rev. 5, 59-65 (2014). https://doi.org/10.1016/j.esr.2014.10.003

Rainie, L., Funk, C.: Americans, politics and science issues. Washington, DC, Pew Research Center. Retrieved in July 2018 from: http://www.pewinternet.org/2015/07/01/americans-politics-and-scien ce-issues/ (2015)

Reimers, C.W.: Labor market discrimination against hispanic and black men. Rev. Econ. Stat. 65(4), 570-579 (1983). https://doi.org/10.2307/1935925

Rita, P., Brochado, A., Dimova, L.: Millennials' travel motivations and desired activities within destinations: a comparative study of the US and the UK. Curr. Issues Tour. (2018). https://doi. org/10.1080/13683500.2018.1439902

Shaw, F.A., Malokin, A., Mokhtarian, P.L., Circella, G.: It's not all fun and games: an investigation of the reported benefits and disadvantages of conducting activities while commuting. Travel Behav. Soc. 17, 8-25 (2019). https://doi.org/10.1016/j.tbs.2019.05.008

Sivak, M., Schoettle, B.: Recent changes in the age composition of US drivers: implications for the extent, safety, and environmental consequences of personal transportation. Traffic Inj. Prev. 12(6), 588-592 (2012a). https://doi.org/10.1080/15389588.2011.605817

Sivak, M., Schoettle, B.: Recent changes in the age composition of drivers in 15 countries. Traffic Injury Prev. 13(2), 126-132 (2012b). https://doi.org/10.1080/15389588.2011.638016

Spears, S., Houston, D., Boarnet, M.G.: Illuminating the unseen in transit use: a framework for examining the effect of attitudes and perceptions on travel behavior. Transp. Res. Part A Pol. Pract. 58, 40-53 (2013). https://doi.org/10.1016/j.tra.2013.10.011

StataCorp. (2017). STATA Structural Equation Modeling Reference Manual. College Station, Texas: Stata Press. Retrieved from: https://www.stata.com/manuals13/sem.pdf

Straub, C., Zhang, Y., Kusyk, S.: Making a life or making a living? Cross-cultural comparisons of business students' work and life values in Canada and France. Cross Cult. Manag. Int. J. 14(3), 174-195 (2007). https://doi.org/10.1108/13527600710775739

Thigpen, C., Handy, S.: Driver's licensing delay: a retrospective case study of the impact of attitudes, parental and social influences, and intergenerational differences. Transp. Res. Part A: Pol. Pract. 111, 24-40 (2018). https://doi.org/10.1016/j.tra.2018.03.002

Publisher's Note Springer Nature remains neutral with regard to jurisdictional claims in published maps and institutional affiliations.

Ali Etezady is a Ph.D. candidate at Georgia Institute of Technology (Georgia Tech) specializing in Transportation Systems and Engineering. He holds a Master's degree in Computational Science and Engineering from Georgia Tech, in addition to another Master's degree in Transportation Planning and Engineering from Sharif University of Technology, Iran. His research interests include econometrics, advanced statistical modeling, and their application in travel behavior and travel demand modeling.

F. Atiyya Shaw is a Ph.D. candidate in Transportation Engineering at the Georgia Institute of Technology. She holds a B.Sc. and M.Sc. in Civil Engineering, and an M.Sc. in Psychometrics. Her research interests center around the improved measurement of transportation system user behavior and performance.

Patricia L. Mokhtarian is the Susan G. and Christopher D. Pappas Professor of Civil and Environmental Engineering at the Georgia Institute of Technology. She has specialized in the application of quantitative methods to the study of travel behavior for nearly 40 years, and is a recent Past Chair of the International Association for Travel Behaviour Research.

Giovanni Circella is a Senior Research Engineer in the School of Civil and Environmental Engineering of the Georgia Institute of Technology, and the Honda Distinguished Scholar for New Mobility Studies and Director of the 3 Revolutions Future Mobility Program at the University of California, Davis. Dr. Circella's research interests include travel behavior, travel demand modeling, travel survey methods, shared mobility and emerging transportation services, autonomous vehicles, sustainable transportation and policy analysis. 


\section{Affiliations}

Ali Etezady $^{1}$ (D) F. Atiyya Shaw ${ }^{1} \cdot$ Patricia L. Mokhtarian ${ }^{1} \cdot$ Giovanni Circella $^{1,2}$

F. Atiyya Shaw

atiyya@gatech.edu

Patricia L. Mokhtarian

patmokh@gatech.edu

Giovanni Circella

gcircella@gatech.edu

1 School of Civil and Environmental Engineering, Georgia Institute of Technology, 790 Atlantic Drive, Atlanta, GA 30332, USA

2 Institute of Transportation Studies, University of California, Davis, 1715 Tilia Street, Davis, CA 95616, USA 